\title{
MÚSICA Y POESÍA. \\ EL ENCABALGAMIENTO LÉXICO EN JAVIER KRAHE
}

\author{
Por \\ Pablo MoÍÑo SÁNCHEZ
}

E suele utilizar el término tmesis para definir el encabalgamiento léxico, esto es, aquel que divide a una palabra, lo que provoca en ella «un sacudimiento que renueva su significación ${ }^{1}$. Tal fenómeno, poco frecuente en la poesía española, suele ponerse de manifiesto en diccionarios y manuales mediante la famosa lira de fray Luis de León:
Y mientras miserable-
mente se están los otros abrasando
con sed insacïable
del no durable mando, tendido yo a la sombra esté cantando.

El procedimiento empleado por fray Luis fue duramente reprobado por los preceptistas: así lo recuerda el autor del trabajo clásico sobre el encabalgamiento en la métrica española, Antonio Quilis $^{2}$, quien señala, no obstante, la más que probable influencia

${ }^{1}$ José Domínguez Caparrós, Diccionario de Métrica española, Madrid: Paraninfo, 1985, pág. 56.

${ }^{2}$ Antonio Quilis, Estructura del encabalgamiento en la métrica española (contribución a su estudio experimental), Madrid: CSIC (anejo LXXVII de la RFE), 1964. Quilis dedica las págs. 88-95 de su estudio al encabalgamiento léxico, pero ya se ofrecen ejemplos en el primer capítulo (págs. 1-54), consagrado al estudio del fenómeno a través de las preceptivas; el mismo autor había publicado antes un estudio más específico y detallado sobre el recurso del agustino en «Los encabalgamientos léxicos en -mente de fray Luis de León y sus comentaristas», $H R$, XXXI 
horaciana que inspiró este recurso del poeta agustino ${ }^{3}$. Por lo demás, las críticas de los comentaristas a fray Luis también llegaron a otros encabalgamientos, no ya léxicos, pero cuya aspereza provocaba un desequilibrio en la lectura de los versos.

En fin, ante la existencia del encabalgamiento, «desajuste entre pausa rítmica y pausa sintáctica» ${ }^{4}$, existen tradicionalmente dos posturas opuestas: la de quienes piensan que la pausa métrica ha de respetarse y la de aquellos que, por el contrario, opinan que el desequilibrio provocado por el encabalgamiento ha de implicar, forzosamente, la desaparición de la pausa rítmica; todas estas opiniones son presentadas y analizadas en su contexto por José Manuel Bustos Gisbert, cuya tesis doctoral, La introducción del encabalgamiento en la lírica española, explora la presencia del recurso en nuestra lírica entre los siglos XV y XVII ${ }^{5}$.

(1963), págs. 22-39. Cf. también su Métrica española [1969], Barcelona: Ariel, 2001, págs. 85-86 y, en fin, otros estudios y manuales clásicos sobre métrica o aspectos relacionados como los de Tomás Navarro Tomás, Dámaso Alonso, Rudolf Baehr, etc.

${ }^{3}$ Cf. Antonio Quilis, Estructura ..., págs. 89-90. Véase también el trabajo de Francisco Senabre "El encabalgamiento en la poesía de fray Luis de León", en RFE, LXII (1982), págs. 39-49, donde se documentan nuevos ejemplos de encabalgamiento léxico en Horacio y Catulo (pág. 41 nota). Por otro lado, Isabel Paraíso ha publicado hace poco un interesante artículo, "La frontera del verso: reequilibrio de sílabas entre versos sucesivos", en Filología y Lingüística. Estudios ofrecidos a Antonio Quilis (2 vols.), Madrid: csic, 2005, págs. 2029-41 (vol. II), donde aclara que en el verso lírico latino se produce la sinafía (sinalefa entre la vocal final de un verso y la inicial del siguiente, hipermétrico: en JRJ, «el campo / florido / pintaba / en tus ojos») en las estrofas de cuatro versos (entre el tercero, sáfico, y el cuarto, adónico). Como estos dos versos iban unidos en su origen griego, los poetas latinos a veces cortan la palabra que los separa (pág. 2034).

${ }^{4}$ Rafael de Balbín, Sistema de ritmica castellana [1962], tercera edición aumentada, Madrid: Gredos, 1975, pág. 202. Véase también Antonio Quilis, Estructura..., págs. 84 y siguientes, donde se recoge esta cita.

${ }^{5}$ Entre los partidarios del mantenimiento de la pausa rítmica -y la realización oral, por tanto, del encabalgamiento-, cabría destacar a Andrés Bello; la postura contraria, la que opta por la supresión de dicha pausa, es defendida por Benot y encabezada más tarde por Antonio Quilis. La tesis doctoral de Bustos, dirigida precisamente por Ricardo Senabre y leída en Salamanca en 1991, parte de la tradición petrarquista italiana, sin olvidar el antecedente de los citados poetas latinos; a los autores cultos del XV como Santillana siguen las muestras, ya mucho más conscientes, que ofrecen Boscán, Garcilaso, Herrera, Francisco de la Torre (en el enigmático poeta castellano se convierte en una auténtica seña de identidad, aunque limitada a los poemas de métrica culta y tema amoroso), Lope, Quevedo y, finalmente, Góngora; los ejemplos del XVII, especialmente los del cordobés, muestran cómo el encabalgamiento, ya asentado en la tradición lírica, deja de ser recurso nove- 
Si bien el valor del encabalgamiento ha sido discutido y cuestionado, atendiendo a criterios rítmicos, los trabajos que destacan su valor semántico $-\mathrm{y}$ con ello toman partido, de manera implícita, por la realización de la pausa versal-son más escasos ${ }^{6}$. Sí se suele incidir, a propósito del encabalgamiento léxico, en las implicaciones humorísticas que a veces conlleva el procedimiento, lo que ha dado lugar a no pocas controversias ${ }^{7}$. En el fragmento calderoniano que sigue:

\author{
Y la otra mitad a cuenta \\ de la primera desca- \\ labradura que se ofrezca.
}

La intención es doble, pues operan juntamente el recurso cómico y el puramente semántico. Por otra parte, no pueden pasarse por alto las diferencias existentes con respecto a la lira

doso o especialmente audaz para pasar al servicio de otros procedimientos como el hipérbaton. Bustos concluye su trabajo tomando partido por la tesis de Bello, que justifica mediante abundantes ejemplos donde queda claro que el componente oral de la poesía, adaptable al ritmo musical, es esencial en la conformación de un ritmo poético que queda sujeto a una función determinada.

${ }^{6}$ El citado artículo de Ricardo Senabre sobre fray Luis muestra la importancia del valor semántico de algunos encabalgamientos del poeta, que en todos los casos -véanse, por ejemplo, muestras como «¿Qué vale el no tocado / tesoro...» o « iY tú, rompiendo el puro / aire...»-marca una distancia «real o subjetiva, cronológica o espacial, entre dos nociones» (pág. 44).

7 José Domínguez Caparrós recuerda que el encabalgamiento léxico «también es una forma de evitar una rima trivial o de lograr un efecto cómico» (Diccionario..., id.). Véase el elegante cruce de argumentos entre Tomás Navarro Tomás y S. G. Morley en RFE, XIII (1926), págs. 71-73, 287-288 y 289-290. Morley, editor de la comedia atribuida a Lope Ya anda la de Mazagatos (aparecida por primera vez en dos volúmenes del $B H I$, de 1923 y 1924), había editado así los versos siguientes: «Con la confusión logré / escaparme, y perdida la senda». En una reseña de la rfe con motivo de esta edición, Felipe Morales de Setién propone el cambio de verso tras esca-, única opción que, pese a la dureza, permite el octosílabo. Al escepticismo manifestado por Morley, que afirma en A note on the Spanish octosyllable, Modern Language Notes, XLI (1926), págs. 182-184 no conocer caso semejante en el XVII, regala Navarro Tomás dos ejemplos de Calderón (págs. 7173), tomados de la Ortología clásica de la lengua castellana (Madrid: 1905) de F. Robles Dégano (que reproduce Quilis, El encabalgamiento..., págs. 34-36; véanse también las págs. 5-16, con más ejemplos). Aduce Morley (págs. 287-288) que los ejemplos de Calderón escogidos por TNT se limitan a fragmentos cuyo carácter burlesco es evidente. Una vez más, TNT contraataca (págs. 289-290) con nuevos ejemplos de fray Luis o Juan Ramón Jiménez donde el encabalgamiento léxico no se emplea con fines humorísticos. 
luisiana, donde la palabra encabalgada, miserable- / mente, es un término con doble acentuación y por tanto soporta mejor la ruptura versal; desca- / labradura, por su parte, nos obliga a realizar una dislocación acentual (descà-) que, en efecto, descalabra el verso por completo . $^{2}$

Una variante de encabalgamiento léxico, muy cultivada por los modernistas, es la que afecta a la cesura; se ha dado en llamar medial. Versos de Darío como y tú paloma arrulladora y montañera... o ¿Cuándo será la cabellera que se inclina..., ambos en un contexto de alejandrinos, obligan a la realización de, respectivamente, y tú paloma arrù- / lladora y montañera... y ¿Cuándo será la cà- / bellera que se inclina..., lo que devuelve, en ambos casos, el isosilabismo a los hemistiquios; procedimientos así son relativamente frecuentes en la poesía actual ${ }^{9}$.

Sirvan de excusa las apreciaciones de Bustos respecto a la relación entre encabalgamiento, oralidad, música y literatura para esta breve nota, cuya intención es la de mostrar cómo se manifiesta la tmesis en las canciones-poemas del cantautor madrileño Javier Krahe. Por si acaso no bastara lo anterior, recuérdense el rigor métrico y la variedad estrófica con que Krahe construye sus canciones: muchos de estos recursos -isosilabismo; rima consonante y, en muchos casos, poco habitual; calambures métricos; mezcla extrema de registros para obtener consonancias impen-

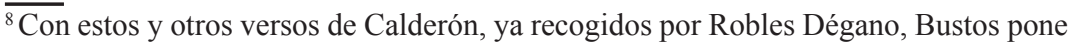
de manifiesto el encabalgamiento léxico sobre unidad monotónica (op. cit., págs. 129-130), utilizado - con poca frecuencia- en el teatro de los siglos de oro (Li- / sardo, hi- / lo, etc.), pero no en la lírica. El encabalgamiento sobre unidad ditónica (págs. 130-131) suele afectar a los adverbios en -mente, pero se documenta por primera vez en Garcilaso, que divide donde- / quiera.

${ }^{9}$ Los dos ejemplos están tomados de Antonio Quilis, El encabalgamiento..., pero son francamente numerosos los casos de este tipo de encabalgamiento, de ascendencia francesa. Rafael de Balbín, que rescata sendos encabalgamientos sobre la cesura en Rubén Darío y Manuel Machado (rèmi- / niscencias y dès- / cansar, respectivamente), señala, con no poca razón, que la dureza de los versos modernistas es mayor que la del célebre ejemplo luisiano, puesto que desarticula, como hemos visto, el sistema fonológico del vocablo. El fenómeno aparece especialmente ligado a versos largos como el tridecasílabo, que casi siempre termina asimilándose, en la cadena rítmica, al alejandrino; véanse, entre otros, los trabajos de Pablo Jauralde Pou, "Tridecasílabos", en Rhythmica, 1 (2003), págs. 125-147; o, más recientemente, José Domínguez Caparrós, "Sonetos tridecasílabos de Unamuno", en el citado homenaje a Quilis, Filología y lingüística..., (págs. 1923-1938, vol. II). 
sables, etc.- provienen de un conocimiento amplio y variado de la tradición poética española ${ }^{10}$; de otro lado, la apuesta decidida por un arte basado en el juego y el humor llevan a Krahe a experimentar con combinaciones formales poco frecuentes en su gremio.

Tampoco analizaré ahora, salvo en los casos en que sea pertinente, la deuda de Krahe para con el cantautor y Grand Prix de Poésie de l'Académie Française en 1967 -esto no debe olvidarse- Georges Brassens, por lo demás perfectamente reconocida por el madrileño ${ }^{11}$. Baste con decir que Krahe toma de Brassens buena parte de las formas estróficas, de tradición simbolista y modernista, y mantiene el juego de ritmos y rimas, con interesantes hallazgos -quebrados, versos agudos, rimas internas-, en las adaptaciones que hace de las canciones del poeta francés: así en "L'orage" (La tormenta) como en "Marinette"

${ }^{10}$ Véase la revisión de mitos y figuras del arte o la literatura en canciones como "Piero della Francesca", "Cuerpo de Melibea", "Salomé”, "Como Ulises", "Esaú", "Once años antes", "Peleas y Melisanda" (que comienza, majestuoso, "A veces pienso en ti incluso vestida»), etc.; o su encendido y sarcástico ubi sunt "Asco de siglo", que termina con los célebres versos «¿Qué se hicieron las llamas / de los fuegos encendidos / de amadores? / ¿Qué se hicieron las damas, / sus tocados y vestidos, / sus olores?». La estrofa manriqueña, los romancillos pentasílabos o, sobre todo, los serventesios de alejandrinos, en ocasiones quebrados a eneasílabos, son algunas de sus estrofas preferidas, en un abanico de posibilidades que llega al octodecasílabo de "Salomé" y parte de las octavillas trisilábicas de "Minimal de amor»: «Señora / que añora / mi mente / doliente, / mi boca / te invoca / si umbrío / sonrío... ». Por otra parte, el comienzo de "Vecindario", antológico, recuerda, por el ritmo $(2.5+2.5)$, a las coplas de Juan de Mena: «Mi esposa padece furor uterino, / no damos abasto ni yo ni el vecino. / Y a mí me da pena del pobre Avelino».

${ }^{11}$ No, esto no debe olvidarse: el reconocimiento de Brassens por la crítica (también literaria) y el público es casi unánime, especialmente en su país de origen. Las publicaciones de o sobre Brassens en la Bibliothèque Nationale parisina son abundantes; se recogen versos del autor en editoriales tan prestigiosas como Seuil (Poèmes et chansons, 1993) o Seghers (Chansons, présentées par Alphonse Bonnafé et Lucien Rioux, 2002); en esta última obra, que se imprime por vez primera, en la colección "Poètes d'aujourd'hui", en 1963, se incluye el texto clásico de Bonnafé (profesor de francés de Brassens en el Collège Paul Valéry de Sète), "L'homme qui rit", págs. 9-37, al que sigue el de Lucien Rioux "Une chanson redevenue libre", págs. 39-57. Son abundantes las obras de contenido biográfico; de entre las últimas, véanse Loïc Richard, Brassens par Brassens, prologue de René Fallet, Paris: Le Cherche Midi, 2005; Éric Battista, Georges Brassens. Entretiens et souvenirs intimes, Barbentane: Équinoxe, 2001; etc. Los textos del autor francés -en adelante, para él y para Krahe, se utilizará el sustantivo poeta- se incluyen en los libros escolares franceses a partir del curso 1969-1970; allí continúan apareciendo, año tras año. 
("Marieta"); asimismo podemos decir que Krahe coincide con Brassens en algo tan abstracto como el estilo musical, donde prevalece, al menos aparentemente, la letra a la melodía; o en temas recurrentes como el adulterio ${ }^{12}$; o en las alusiones escatológicas; o en la asunción del registro coloquial-más-bien-vulgar, siempre producto de la reflexión y el trabajo con la palabra ${ }^{13}$. Por el momento, es suficiente con mostrar que el recurso de la tmesis aparece en Brassens en canciones como «La non-demande en mariage»:
J'ai l'honneur de
Ne pas te de-
mander ta main,
Ne gravons pas
Nos noms au bas
D'un parchemin

Como vemos, se lleva a cabo en versos breves, concretamente pentasílabos, en los cuales la rima $a a b c c b$, clásica, se logra mediante el encabalgamiento léxico de una palabra relativamente larga, el verbo demander. En este sentido la tmesis permite a Brassens ajustar la medida de los versos y obtener un efecto cómico. Será este uno de los procedimientos preferidos de Javier $\mathrm{Krahe}^{14}$, que utiliza habitualmente el encabalgamiento léxico con

${ }^{12}$ Una canción de Brassens se llama, precisamente, "Le cocu" (el cornudo); Corral de cuernos es el título de uno de los álbumes de Krahe. Se trata de un simple botón; en el madrileño hay numerosas canciones dedicadas al adulterio, casi siempre conocido y en ocasiones deseado: "Sábanas de seda", "Vecindario", etc.

${ }^{13}$ Las publicaciones sobre Javier Krahe no son tan abundantes. Sí es destacable su inclusión, en calidad de juglar, en una editorial dedicada exclusivamente a la poesía: Javier Krahe, Todas las canciones, Madrid: Visor, 2003. Puede consultarse la monografía de Ángel Vivas Javier Krahe, Barcelona: Júcar, 1991, especialmente las págs. 47-54, donde habla el poeta y explica el proceso creativo de la primera estrofa de una de sus canciones quizá más bellas, "Sábanas de seda", aunque de tono radicalmente distinto al que Krahe suele manejar, esta vez más parecido a "Nos ocupamos del mar" o "Paréntesis", es decir, marcadamente lírico. En estas páginas Krahe expresa algunas de sus preocupaciones técnicas y su rigidez en la elección o sustitución de algunos términos por otros.

14 La discografía de Krahe se inicia con Valle de lágrimas (1980), álbum al que siguen La Mandrágora (1981, grabado en directo, en el bar del mismo nombre, con Alberto Pérez y Joaquín Sabina); Aparejo de fortuna (1984); Corral de cuernos (1985); Haz lo que quieras (1987); Elijeme [sic] (1988); Sacrificio de 
versos cortos, preferentemente hexasílabos, como en las dobles sextillas de "Ovnis", donde sigue, por cierto, el mismo esquema métrico $a a b c c b$, siempre con $a$ y $c$ agudos (págs. 44-46):

Que el año 2000
-a la luz de un candil--
los supervivientes
no vean más plan
que un terrible llan-
to y crujir de dientes
se puede apostar,
sin menospreciar
a aquellos profetas
que aseguran que
el remedio vie-
ne de otros planetas.
$\quad$ Una nueva fe
a la escala de
nuestro pobre ingenio,
una solución
de ciencia ficción
de cara al milenio:
que un rayo de luz
celeste conduz-
ca al hombre expectante.
¿Quién no ha visto algún
vulgar y común
platillo volante?

dama (1993); Versos de tornillo (1997); Dolor de garganta (1999); Cábalas y cicatrices (2002); y, recientemente, Cinturón negro de karaoke (2006), amén del recopilatorio no oficial de Surtido selecto (2000). Poco antes de la aparición de su último disco, recibió el homenaje de sus compañeros en el doble álbum ...Y todo es vanidad, donde casi cuarenta artistas interpretan las canciones del madrileño. A partir de ahora señalo entre paréntesis, cuando proceda, las páginas de Todas las canciones donde aparecen los versos citados; en contadas ocasiones modificaré la puntuación, no siempre correcta.

${ }^{15}$ No se habrá pasado por alto la hipermetría del segundo verso, algo sin duda muy poco frecuente en las canciones de Krahe, y que el autor resuelve reduciendo la cantidad de las dos primeras sílabas a una sola; por otro lado, es mayoritaria la acentuación en 2.5, lo cual colabora en esta artimaña. La tmesis continúa a lo largo de la canción: "Que hay ovnis y tal / no creo que haga fàl- / ta que lo demuestre»; y, en la última estrofa, «De ahí el interés / del extraterrès- / tre por nuestra escena». 
Idéntica medida, idéntico juego de agudas y llanas nos ofrece «Un trivial comentario» (págs. 55-56); esta vez se da un paso más en el virtuosismo métrico, puesto que las sextillas siguen ahora el esquema aabaab-Era un inmoral, / un libre animal / fornicario / que en su bacanal / asustaba al / vecindario-, y las estrofas no cambian de rima. El encabalgamiento léxico aparece pronto, en la tercera sextilla:

proclamaba en al-

ta voz «lo ideal

es lo vario

y que cada cual

se guarde su al-

ma en su armario».

Sin embargo, el protagonista se enamora, abandona su vida de excesos y se dispone a vivir con calma (o aburrimiento); la canción concluye con la moraleja esperable:

\author{
El gran pasional \\ se hizo marital \\ funcionario \\ y encontró la cal- \\ ma sentimental \\ a diario ${ }^{16}$.
}

por más que en los últimos versos Krahe nos diga: No tiene moraleja / este trivial comentario. La distribución, claramente errónea, aparece así, de modo inexplicable, en Todas las canciones, pese a que se trata de uno de los ejemplos que de mejor manera ponen de manifiesto la importancia de la tmesis para Krahe ${ }^{17}$.

\footnotetext{
${ }_{16}$ Antes había aparecido de nuevo la tmesis: «Como es natural / desechó el bestial / ideario / diciendo " es normal / porque este era al- / go precario"».

${ }^{17} \mathrm{Y}$ es inexplicable, sobre todo, porque en el mismo volumen se ha señalado un encabalgamiento léxico hemistiquial, algo poco frecuente y que no deja lugar a dudas acerca de la importancia que Krahe otorga al recurso. Véase "Zozobras completas", de ritmo heptasílabo y rimas aBccB, donde los alejandrinos tienen rimas internas, respectivamente, en $a$ y $c$ : «Unas doce, tal vez, / surgirán, qué escasez, si a las seis sedujera, / porque hay cara y hay cruz, / porque hay sombra y hay luz, / y si no las seduz-co, a saber qué me espera». El guión muestra que Krahe pretende transmitir, al menos en este caso, el efecto rítmico al lector.
} 
En efecto, al verso No tiene moral $1{ }^{18}$, aparentemente completo o unitario, sigue la sorpresa del lector-oyente: ...moral- / eja este trivial / comentario. La pausa coincide con el fin de una palabra que no es tal, lo que provoca un efecto inesperado: se trata de un encabalgamiento léxico oculto. Exactamente lo mismo que sucede en otros versos del autor:

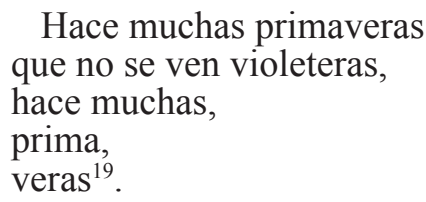

donde Krahe juega con el vocativo esperado y lo convierte en comienzo de otra palabra. Huelga decir que también aquí la fuerza -el efecto mayor- de los versos que se atienen al encabalgamiento procede de su carácter oral.

Si la tmesis contribuye, en ocasiones, a deshacer rimas triviales, a Krahe le sirve para, de modo ingenioso, encontrarle rima a las palabras sin ella: las fénix ${ }^{20}$. De este modo solventa el problema de la consonancia con una de las palabras tradicionalmente únicas, en versos eneasílabos:

Me internarán por mucho tiempo
hasta que sane y aún después
en el manicomio de Ciempo-
zuelos o en el de Leganés ${ }^{21}$.

${ }^{18}$ Cantado por Krahe, como en todos los ejemplos de esta nota, con su pausa versal obligatoria; la realización rítmica de la tmesis es ineludible para el poeta.

19 En El hombre y el oso y el Madroño, pág. 78. En cierto modo sucedía lo mismo en cal- / $m a$, pero su efecto era mucho menor; véanse, también, los eneasílabos finales de "El lirón": «No pudo ni siquiera ver / la ruina de su madriguera. / Sólo exclamó: “¡Hay que joder- / se, ya está aquí la primavera!”».

20 Véase José Domínguez Caparrós, Diccionario..., pág. 105; el estudioso recuerda que el término procede de la singularidad del ave, única en el mundo; fénix es, además, palabra fénix por su rima exclusiva.

${ }^{21}$ En "Me internarán", escrita con motivo del célebre revuelo que provocó la censura a su canción "Cuervo ingenuo" por parte de Televisión Española (págs. 99-100); otras veces el estribillo cambia el segundo verso por «pongamos por tres años, tres; hasta volverme del revés; si no salgo campo a través; y ya lo dijo el Eclesiastés». En "Cuervo ingenuo", por cierto, Krahe rima votan con OTAN; otros acrónimos, topónimos, nombres de medicamentos, expresiones coloquiales, etc. 
Otras veces las palabras fénix aparecen quebradas por la tmesis, con lo que precisamente ya no son tales; en el ejemplo siguiente, el doble encabalgamiento léxico salva la monotonía de una rima en infinitivo:

Iré a nadar
en el río y a enfrentar-
me con un cocodrilo,
tendré mi hogar
en la copa de un gran ár-
bol y desde allí vigilo 22 .

"Esaú", construida en eneasílabos que por momentos quiebran a metros más breves (pentasílabos, tetrasílabos), es una de las canciones de Krahe donde el encabalgamiento léxico cobra mayor importancia y nos muestra todas sus variedades: situado al comienzo o al final de la palabra (a veces la misma, lo cual no es anecdótico: primogenitù- / ra en la primera estrofa; prì- / mogenitura en la última, antes del estribillo final); con rimas triviales ( $o-/$ portuno con ;No), relativamente difíciles (acidez con merèz- / ca) o imposibles (ob- / nubila con Jacob), que se unen a las endiabladas mayorazgo-hartazgo y usufructo-eructo, es el recurso más destacado de esta canción de tema bíblico en la cual podemos encontrar varias de las características ya apuntadas sobre el estilo de Krahe:

son colocados en rima por el autor en muchas de sus canciones, a veces con leve dislocación acentual: así, entre muchas otras -la lista es interminable-, UVI-cantidubi, tarumba-tumba o jersey-Hemingway ("Nembutal"); cueritatis-gratis ("San Cucufato"); volumen-cacumen ("El tío Marcial"); Jesús-repelús ("Los caminos del Señor"); streeptease-mis ("Zozobras completas"); cisnes-show business ("Los siete pecados capitales"; aloha-proa ("Mi polinesia"); escabechina-benzodiacepina, emocional-Orfidal, Mojácar-nácar o qué va-Alá ("Orfidal"); sol-crawl ("En la costa suiza"); fijate tú-amor fou ("Sábanas de seda"); caray-ahi ("El topo", en pronunciación relajada); paranoias-gilipollas ("Pues... nada, hombre"); etc. En Brassens son muy frecuentes este tipo de rimas: turlututu con défendu, manitou con rien du tout, Jérusalem con à l'heure blême, etc.

22 "De liana en liana", pág. 165; el ritmo de los versos, no especialmente memorables esta vez, es más bien difuso. En el último disco de Krahe, Cinturón negro de karaoke, la tmesis sigue siendo característica, sobre todo en metros breves, en ocasiones con idéntica rima en infinitivo: «En fin, / que me fui sin / haberlo averiguado / al ár- / tico polar / a comerme un helado» (“i"Amos, anda!"); o en los versos con ritmo de seguidilla de "Eros y civilización": «Los dos sabemos bien, / muy bien los dos, / que ya no viene a cuen- / to, así que adiós». 
Todos los días, Esaú, vendes tu primogenitura por un plato de lentejas. Luego, te quejas.

Entonces gritas: ¡al ladrón, Jacob me roba el horizonte y el valor y el desafío, cuanto era mío!

Pero otras veces la acidez no te parece que merezca el grito y tragas tras el trato bicarbonato.

Esaú, si las lentejas con su hechizo no te han llenado hasta el hartazgo, ten un poquito de ambición.

Esaú, so tragón, que al menos sean con chorizo.

Olvida ya tu mayorazgo y que hagas buena digestión.

Mira qué fácilmente te obnubila tu hermano Jacob y casi sin tú darte cuenta le haces la venta.

Para ti nunca el día es oportuno para decir: ¡No, hermano, vete a la puñeta, me pongo a dieta!

¿Quieres decirme qué es la primogenitura para ti,

acaso vale su usufructo

lo que un eructo?

Esaú, si las lentejas con su hechizo

no te han llenado hasta el hartazgo

ten un poquito de ambición.

Esaú, so tragón,

que al menos sean con chorizo.

Olvida ya tu mayorazgo

y muérete de indigestión. 
Por último, el encabalgamiento léxico medial, muy utilizado en la poesía contemporánea, es también el más cultivado por el poeta madrileño. Más arriba, a propósito de cierta distribución errónea de los versos en Todas las canciones, apunté que el autor se interesa por apercibir a sus lectores del artificio empleado. Con todo, no siempre quedan al descubierto las costuras; véase el comienzo de "Sr. Juez":

Sr. Juez: nada más le quería decir que en el día de hoy, cansado de vivir, me decido a causar mi baja, la eterna, la fetén, me excluyo del padrón y aquí a renglón seguido le expongo la razón por la cual rompo la baraja.

No piense en una tragicomedia de amor, que sufro un cáncer y no soporto el dolor, que rechazo ir a un asilo, que perdí la razón, la potencia sexual, que estoy a fin de mes, que si tal que si cual, ni otras cosas por el estilo ${ }^{23}$.

cuya segunda estrofa se abre con un verso donde opera la tmesis sobre la cesura: no piense en una trà- / gicomedia de amor; y en la que son mayoritarios, por no decir obligados, los hemistiquios agudos ${ }^{24}$. El final de la canción sorprende al lector-oyente, aunque no al mismo tiempo. Tras la justificación del suicida, afectado de la célebre opresión / entendida en sentido lato, este concluye y acusa al juez: Mi asesino es Vd., por qué no lo iba a ser, / representa la ley, simboliza el poder, / el poder y quien se lo harroga... El lector de Todas las canciones, entonces, se extraña de esa hache equivocada, y tal vez lo achaca a los correctores del

$\overline{23}$ Pág. 47; la canción termina en la 48. La estrofa, sexteto de alejandrinos y eneasílabos, combinación tomada de Brassens (véase "La tormenta", de esquema idéntico) y muy querida por Krahe, mantiene la rima de otras veces, AABCCB, con A y $\mathrm{C}$ agudos.

${ }^{24}$ Salvo y aquí a renglón seguido le expongo la razón, que, con todo, soportaría una lectura con tmesis tras segui- y acortamiento silábico en do le. No es caprichosa esta lectura: encontraremos otras tmesis mediales obligatorias en «me va muy bien en to- / do con la salvedad o creer [crecer, por error, en Todas las canciones] que si me ahor- / co tengo libertad». 
volumen, o al despiste, o al signo de los tiempos; el oyente, por su parte, no percibe nada, pues la letra en cuestión es muda. Sin embargo, la última estrofa aclara a ambos públicos:

Aquí ya me indigné; di la carta al ujier:

«Archive esto por ahí»; no lo podréis creer:

¡escribía arroga con hache!

Y las faltas así, desde hace ya algún tiem-

po, es que no las aguanto, me ponen a cien.

Estaré atravesando un bache...

El mayor logro, sin duda, de la canción, el eneasílabo jescribía arroga con hache!, viene seguido de dos versos con sendos encabalgamientos léxicos en boca del juez (hasta entonces, hemos visto que habla el suicida): uno opera al final de verso -tièm- / po-, quebrando la fénix, y el otro se sitúa sobre la cesura, acentuando el gerundio, aguàn- / to ${ }^{25}$. De este modo, Krahe encadena dos tmesis seguidas, las dos únicas de la composición, algo que se repite en otros lugares: así en "El tío Marcial", de nuevo en la última estrofa y con otro error de disposición versal:
Y la próxima vez te juro que seré, oh patria, algo más práctico: te dejaré un borrego, una fotonovela y una flor de plástico ${ }^{26}$.

Aparentemente, el cuarteto respeta la medida -es necesaria, en ese caso, la dialefa y'una-; sin embargo, los versos primero y

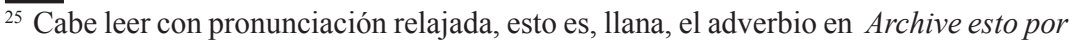
$a h i$; no obstante, y puesto que los hemistiquios han de ser agudos, puede funcionar la cantidad silábica, como en la nota anterior. El hecho, patente en la realización musical del poema, genera tal vez mayores reservas en la lectura; con todo, el ritmo de los versos es indiscutible.

${ }^{26}$ Formada por cuartetos de alejandrinos y heptasílabos AbAb, con A aguda (págs. 2223). Se trata de una de las pocas veces que Krahe no respeta escrupulosamente la consonancia; en la misma canción se permite idéntica licencia rimando las fénix mármol y árbol; por otro lado, también rima los complicados binomios huéspedcésped y volumen-cacumen. Rara vez se permite Krahe asonancias en vocales débiles: estéreo-adulterio ("Vaya por delante"), Venus-menos ("Villatripas"); o en consonantes finales poco frecuentes: recién-avecrem ("Zozobras completas"); ejem-sostén ("Olé tus tetas"); etc. 
tercero han de rimar, como en el resto de estrofas de la canción: es decir, debemos leer (y escribir), ya sin dialefa, te dejaré un borrego, una fotonovè- / la y una flor de plástico; por otro lado, y por la misma razón, el primer hemistiquio finalizará no tras borrego, sino tras borrè-, con lo cual vuelven a encadenarse dos encabalgamientos léxicos, el primero de ellos medial.

No es, ni mucho menos, extraño este recurso; no en Krahe. Véase, para finalizar, el comienzo de una de sus canciones más conocidas, "Don Andrés octogenario":

Podemos decir que, sin exageración, era algo extraordinario

la enfermera que cuidaba al bueno de don Andrés octogenario ${ }^{27}$.

que exige cesura tras cui-; más adelante Krahe jugará con nuevos encabalgamientos léxicos mediales en El abuelo, que enfrèn- / taba con resquemor; Y fue al desabrochàr- / se ella el quinto botón; Y al entierro tampò- / co porque al ataúd; o La muerte lo abrazà- / ba de un modo especial, entre otros. En todos estos casos, en todos los anteriores, es importante señalar dos cosas, ambas relativamente obvias. Primera: el autor, como cualquier otro poeta, jamás separa gráficamente (en Todas las canciones) las palabras que cabalgan sobre la cesura; la única excepción, apuntada más arriba en nota $-y$ si no las seduz- co...-, pretendía poner de relieve la rima. Segunda (que puede servir como resumen de estas páginas): la realización de la tmesis se lleva a cabo, en las canciones de Krahe, de manera lo suficientemente marcada como para provocar un efecto en el lector-oyente ${ }^{28}$. La música y la literatura se sirven de recursos técnicos diferentes, de acuerdo; pero quizá haya pocos que las acerquen tanto, hasta casi superponerlas, como el encabalgamiento.

$\overline{27}$ De nuevo alejandrinos agudos y quebrados llanos, esta vez heptasílabos (págs. 1415). Quedará para otra ocasión el inventario de estrofas clásicas utilizadas en las canciones de Krahe; por el momento es suficiente, espero, esta pequeña muestra para dar cuenta del interés del autor por la experimentación con diversos ritmos y su dominio de la forma poética.

${ }^{28} C f$. Isabel Paraíso, art. cit., donde se analizan diversas variantes de reequilibrio silábico entre versos, que suponen, para la autora, «el abandono del poeta a su música interna» (pág. 2040). 